\title{
In Memoriam: J. Peter Rosenfeld 1940-2021
}

\author{
Richard Gevirtz $^{1} \cdot$ Neils Birbaumer ${ }^{2} \cdot$ Tato Sokhadze $^{3}$
}

(c) Springer Science+Business Media, LLC, part of Springer Nature 2021

The worlds of Psychology, Psychophysiology and Applied Psychophysiology have lost a pioneer and a major figure in our colleague, friend and mentor Peter Rosenfeld. The article entitled "Bayesian Data Analysis: A Fresh Approach to Power Issues and Null Hypothesis Interpretation," by J. Peter Rosenfeld and Joseph M. Olson, which is included in this June 2021 issue, was submitted to our journal last November by Peter. It is notable, not because it added to his outstanding contributions to the detection of deception (including several seminal publications in our journal), but because it reveals a wonderful aspect of Peter's skill set and personality, his joy of teaching. In this article Peter sought to help our readers manage the ever-changing trends in statistics and research design. He brilliantly outlines the Bayesian alternative to null hypothesis testing. It was clear that he wrote this as a service to his colleagues in the applied psychophysiology and biofeedback fields.

Peter was one of the first scientists in the seventies and eighties who understood the potential of biofeedback: he trained people to increase and decrease pain evoked brain potentials and demonstrated a correlated change in pain sensation. What was even more surprising that he isolated the neurophysiological component of the pain evoked brain potential excluding unspecific arousal effects. This had a strong stimulating effect on the psychophysiological community to investigate the behavioral and neuronal mechanisms behind physiological regulation through learning more deeply.

This early work with self-regulation and neurofeedback of evoked brain potentials paved the way for the question he

Richard Gevirtz

rgevirtz@alliant.edu

1 CSPP@Alliant International University, San Diego, CA, USA

2 University of Tübingen, Tübingen, Germany

3 University of South Carolina School of Medicine, Greenville, SC, USA investigated with his students at Northwestern over many years of our ability to "beat" a lie detector based on recordings of the P-300 brain response to crime relevant and irrelevant stimuli. If people are able to self-regulate their brain activity milliseconds after presentation of a stimulus why can't "they beat" the lie detector with such a self-regulatory skill? He continued to demonstrate the conditions under which detection of deception works and under which conditions it fails. With this work Peter contributed substantially to a scientifically based discussion of the use and misuse of psychophysiological measures in the detection of deception.

On a more personal note, Peter was a valued friend and colleague. He had a magnificent grasp of music, the arts, and so many other areas. We were the beneficiaries of his unique and wonderful sense of humor. He will be missed!!

Richard Gevirtz, PhD, BCB

Neils Birbaumer, $\mathrm{PhD}$

Tato Sokhadze, PhD

Publisher's Note Springer Nature remains neutral with regard to jurisdictional claims in published maps and institutional affiliations. 